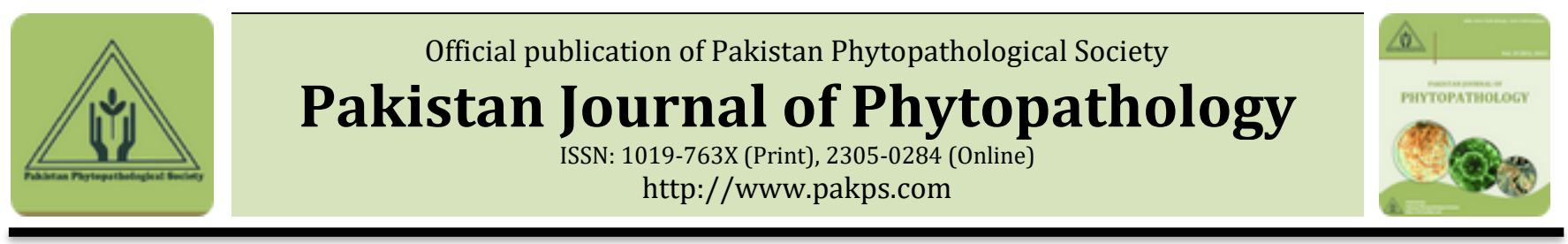

\title{
VARIATION IN AGGRESSIVENESS OF FUSARIUM HEAD BLIGHT SPECIES TOWARDS BARLEY PLANTS DETERMINED USING THREE IN VITRO ASSAYS
}

\author{
Nachaat Sakr \\ Department of Agriculture, Atomic Energy Commission of Syria, Damascus, P.O. Box 6091, Syria.
}

\section{A B S T R A C T}

Aggressiveness is the most important fungal trait affecting Fusarium head blight (FHB) disease invasion and stability of host resistance. Until recently, in vitro methodologies have proved to be very useful in analyzing disease responses in barley plants to FHB infection. To update our knowledge, the variation in aggressiveness for 16 isolates of four FHB species was assessed towards two barley cultivars varying in resistance to FHB. Nine aggressiveness criteria involved in three in vitro assays were used: incubation period, latent period (LP), lesion length (of detached leaf and clip-

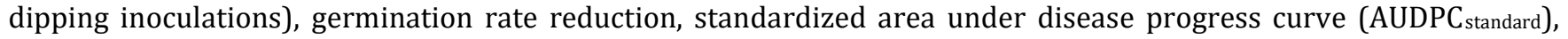
coleoptile length reduction of Petri-dish inoculation, and percentage of infected seedlings (of foliar-spraying and pinpoint inoculations). Differences in inoculated treatment were observed on young plant parts relative to water controls. Inter and intraspecific differences in aggressiveness were observed towards barley plants as measured by LP

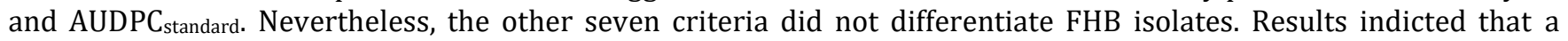
cultivar-specific aggressiveness do not exist among barley plants and pathogens for LP and AUDPC $\mathrm{standard}_{\text {. Significant }}$

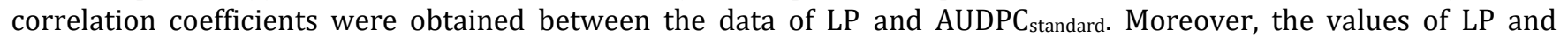
AUDPC $C_{\text {standard }}$ were significantly correlated with the data of disease incidence generated under controlled and field conditions. It seems that LP and AUDPC $C_{\text {standard }}$ are indicators of aggressiveness occurring in the whole plant during FHB infection. To our best knowledge, this is the first in vitro research full analyzing aggressiveness of four FHB species on barley plants. In addition, our study investigates the potential use of in vitro indices in predicting FHB data generated under controlled and field conditions.

Keywords: barley cultivar, detached leaf assay, FHB species, pathogenic variation, Petri-dish assay, seedling assay.

\section{INTRODUCTION}

Fusarium head blight (FHB) is one of the world most noxious barley (Hordeum vulgare L.) disease in humid and semi-humid areas. FHB species infect barley after anthesis and invades into the developing caryopsis resulting in symptomatic bleached spikes which is due to premature death of tissues (Parry et al., 1995). Diseased spikes are sterile or contain deformed, shrunken in various scales and rose pale color grains. When favorable environmental conditions enable severe and frequent epidemics, FHB causes sever reduction in grain

\begin{tabular}{l} 
Submitted: December 12, 2018 \\
Revised: May 26, 2019 \\
Accepted for Publication: May 27, 2019 \\
* Corresponding Author: \\
Email: ascientific@aec.org.sy \\
C 2017 Pak. J. Phytopathol. All rights reserved. \\
\hline
\end{tabular}

yield and quality by producing mycotoxins that lead to technological problems of malt production and brewing quality (Parry et al., 1995; Nielsen et al., 2014).

The infestation of barley is used to be caused by at least seventeen species within the Fusarium genus and two Microdochium pathogens, mainly by $F$. graminearum (Parry et al., 1995; Xue et al., 2006). Other fungi including $F$. crookwellense, F. culmorum, $F$. equiseti, $F$. poae and $F$. sporotrichioides are also involved in FHB infection of barley. Although F. verticillioides and $F$. solani are known to cause rot diseases in many crops worldwide, these species were isolated from head blight infected wheat samples in Argentina (De Galich, 1997), India (Saharan et al., 2003) and Syria (Sakr, 2017b). However, the composition of the FHB complex is considered to vary as a consequence of weather conditions occurring especially during plant anthesis as 
well as by previous crop and agricultural practices, such as pesticide applications and nitrogen fertilization (Backhouse and Burgess, 2002). Barley resistance to FHB is complex and non-race-specific character controlled by quantitative trait loci, i.e., the same plant cultivars display an equivalent ranking against all pathogen isolates (Canci et al., 2004; Chrpova et al., 2011).

Aggressiveness, the extent to which it can attack a susceptible host, is the most important fungal trait affecting FHB disease invasion and stability of barley resistance. However, the expression of aggressiveness and quantitative resistance is not only controlled by the broad range of Fusarium species associated and the host, but also by the environment and their interactions (Xue et al., 2006; Xu and Nicholson, 2009). In a single location, aggressiveness is not geographically structured since fungal isolates with low, medium, and high levels of aggressiveness make up the population for a given FHB species (Backhouse and Burgess, 2002; Xue et al., 2006; Bilikova and Hudec, 2014; Garmendia et al., 2018). However, little information is available on the comparative aggressiveness of species associated with FHB on barley (Xue et al., 2006). Parry et al., (1995) showed no strong evidence for cultivar-specific aggressiveness in the FHB complex. More effective and accurate disease evaluation methods should be sought for successful identification of aggressiveness in FHB species. Till now, traditional screening of FHB aggressiveness requires that barley plants to be grown to mid-anthesis stage prior to inoculation and for an additional 2 to 3 weeks before they are scored for visual head symptoms (Parry et al., 1995; Chrpova et al., 2011). The disadvantages were resulted of being difficult, expensive for performing, needing a large space and appropriate equipments over several years and in environment factors, and being subject to the presence of other competing fungi which may suppress or enhance the activity of the inoculated isolates. Moreover, barley phenotyping is even more complicated than in wheat (Parry et al., 1995; Wu et al., 2005; Chrpova et al., 2011). Until recently, in vitro Petri-dish, detached leaf and seedling assays have commonly been used to assist in screening for FHB resistance in wheat and barley (Mesterhazy, 1978; Browne and Cooke, 2005; Shin et al., 2014; Sakr, 2018c, 2019). Incubation period, latent period, lesion length, percentage infection and dwarfing are quantitative resistance components in the mentioned above assays measured also as indicators of aggressiveness (Lannou, 2012). Indeed, in vitro disease severity in infected seedlings, lesion length and standardized area under disease progress curve have been shown to be useful tools in predicting aggressiveness of several FHB species at early stage in barley (Hestbjerg et al., 2002; Opoku et al., 2011; Sakr, 2018b). Notwithstanding, disease intensity as measured by other in vitro tools in FHB species has not been reported until now.

Ideally, two or more experiments should be conducted, and the data should be compared to examine whether the ranking in aggressiveness is stable. At present, using more than one experiment to analyze aggressiveness of FHB isolates on barley has not been communicated as compared with some FHB-wheat reports (Wu et al., 2005; Purahong et al., 2012; Sakr, 2017a, 2018e,f). In Syria, the incidence of FHB on barley has not reported. But, FHB species are frequently recovered form infected wheat fields (Sakr, 2017b). Recently, Sakr (2018b) reported that FHB cultures isolated from symptomatic wheat spikes showed a similar range of aggressiveness on barley cultivar Arabi Aswad and durum wheat cultivar Cham7 plants in vitro. Syrian barley production is entirely based on two old cultivars: Arabi Aswad (black seeded, AS) and Arabi Abiad (white seeded, AB). AS is used mainly for livestock feed and $A B$ for malting and brewing industry. AS is adapted to drier areas and popular in the northeast Syria. $\mathrm{AB}$ is adapted and primarily planted in the wetter areas in western and northwestern (Bishawa et al., 2015). In this context, we evaluated aggressiveness variability in FHB species complex using three in vitro detached leaf, Petri-dish and seedling assays on two Syrian barley cultivars widely cultivated along the Fertile Crescent, a high biodiversity region where most temperate-zone cereal agricultural species originated and were first domesticated. Moreover, we examined the relationship between the current findings and head inoculation assays generated under controlled and field conditions.

\section{MATERIALS AND METHODS}

Fungal isolates and barley cultivars: Sixteen fungal isolates representing the four Fusarium species ( $F$. culmorum (F1, F2, F3, F28 and F30), F. verticillioides (synonym $F$. moniliforme) (F15, F16, F21 and F27), F. solani (F7, F20, F26, F29, F31 and F35), and F. equiseti (F43)) were recovered from wheat spikes with FHB symptoms originating from Ghab Plain, one of the principal Syrian wheat production areas, during 2015. 
All isolates have been identified by morphological tools (Nelson et al., 1983). For long term preservation, fungal cultures were maintained in sterile distilled water at 4 ${ }^{\circ} \mathrm{C}$ and freezing at $-16{ }^{\circ} \mathrm{C}$ (Sakr, 2018d).

Aggressiveness testing was performed using two Syrian genetically different barley cultivars: Arabi Aswad (AS) and Arabi Abiad (AB) with highest agronomic characteristics (Ceccarelli and Grando, 2000). AS is more resistant to FHB progression than AS detected using in vitro methodologies (Sakr, 2018c) and under controlled and field conditions (Sakr, unpublished data).

Aggressiveness tests: The capability of fungal isolates to confer in vitro FHB symptoms on young plant organs was examined using a detached leaf assay described by Browne and Cooke (2005), a Petri-dish assay according to Purahong et al., (2012), and a seedling assay reported by Shin et al., (2014).

Detached leaf inoculation assay: Surface-sterilized barley seeds were sown in sterile soil using a 3 seeds/9$\mathrm{cm}$ pot in a growth chamber at $20{ }^{\circ} \mathrm{C}$ during day and night with a $16 \mathrm{~h}$ photoperiod. Leaves were harvested after 14 days and $4 \mathrm{~cm}$ length segments were cut from the midsection of the primary leaves. Then, they were placed (adaxial surface facing up) on the surface of Petridish containing artificial media (four leaves per Petridish). Leaf segments were inoculated at the middle of the upper surface with $10 \mu \mathrm{l}$ inoculum suspension of $1 \times$ $10^{6}$ conidia/ml. Control leaves were treated with $10 \mu \mathrm{l}$ sterile distilled water. Petri dishes were incubated at 25 ${ }^{\circ} \mathrm{C}$ with a $12 \mathrm{~h}$ photoperiod. Examination of symptom appearance and sporulation evaluations were carried out under a stereo microscope ( $\times 40$ magnification). Three aggressiveness criteria were assessed: incubation period (days from inoculation to first appearance on the leaf surface, of a dull gray-green water-soaked lesion), latent period (days from inoculation to sporulation), and lesion length (measured after 7 days as a visible chlorotic area). Three replicates of each isolate based on observations on 120 detached leaves were set up, and the experiment was conducted twice.

Petri-dish inoculation assay: Sterilized barley seeds were inoculated with a suspension of conidia at $1 \times 10^{6}$ conidia/ml (or sterile distilled water in the control treatment) for 16 fungal isolates in Petri-dishes with sterile double-layer filter paper. Three aggressiveness criteria: germination rate reduction, standardized area

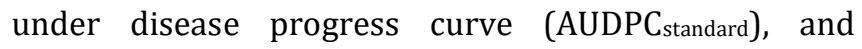
coleoptile length reduction were evaluated. Three replicates of each isolate were set up, and the experiment was repeated. Infected and control treatments were incubated in an incubator at $22{ }^{\circ} \mathrm{C}$ in the dark. Germination rate reduction and coleoptile length reduction were determined by comparison with the control treatment at 6 days after inoculation. The value of AUDPC $_{\text {standard }}$ ranged from 0 (not aggressive) to 1 (very aggressive). It was calculated from the percentage of healthy coleoptiles as a function of time (from 2 to 6 days after inoculation).

Seedling inoculation assay: The percentage of infected seedlings was sassed using pin-point and foliar-spraying tests. Lesion length was sassed using a clip-dipping test. In pin-point experiments, barley seedling stems were inoculated 3 days after sowing by pin-point wounding with $10 \mu \mathrm{l}$ of a suspension of conidia at $4 \times 10^{4}$ conidia $/ \mathrm{ml}$, and sterile distilled water in the control treatment. Twenty seedlings were grown in an incubator $\left(20^{\circ} \mathrm{C}\right.$ during day and night; $12 \mathrm{~h}$ light). The percentage of infected seedlings with visible necrotic lesion and/or sporulation of fungal disease symptoms was measured 7 days after inoculation. In foliar-spraying experiments, seedlings were sprayed 10 days after sowing on both sides of leaves with a conidial suspension at $4 \times 10^{4}$ conidia/ml using an atomizer. Twenty seedlings were grown in an incubator operated with constant $100 \% \mathrm{RH}$ of and $25{ }^{\circ} \mathrm{C}$ for 3 days and then returned to growth chamber for disease evaluation. Sterile distilled water was applied on the control seedlings. The percentage of infected seedlings was measured 7 days after inoculation. In clip-dipping experiments, the tip of barley seedling stems were cutoff 10 days after sowing and then dipped in $20 \mathrm{ml}$ of a suspension of conidia at $4 \times 10^{4}$ conidia/ml for 3 times. Inoculated seedlings were kept covered for 3 days using polythlene bags to provide constant high humidity and then moved to a growth chamber for disease evaluation. Controls were dipped with sterile distilled water only. Lesions on the inoculated leaves were measured at 7 days after inoculation. For these three experiments, three replicates of each isolate were set up, and the experiment was conducted twice.

\section{STATISTICAL ANALYSES}

Data were subjected to analysis of variance (ANOVA) using StatView, $4.57^{\circledR}$ Abacus Concepts, Berkley, Canada. Before statistical analysis, the percentages of germination rate reduction, coleoptile length reduction and infected seedlings were transformed using the angular transformation to stabilize variances. Fisher's LSD test at 
$\mathrm{P}>0.05$ was used to differentiate aggressiveness of $16 \mathrm{FHB}$ isolates. The sample correlation coefficients (Pearson $r$ ) were calculated using overall mean values per isolates at $\mathrm{P}>0.05, \mathrm{P}>0.01$ and $\mathrm{P}>0.001$.

\section{RESULTS}

Overall, exposure of treatments for the nine aggressiveness criteria on $\mathrm{AS}$ and $\mathrm{AB}$ to $16 \mathrm{FHB}$ isolates

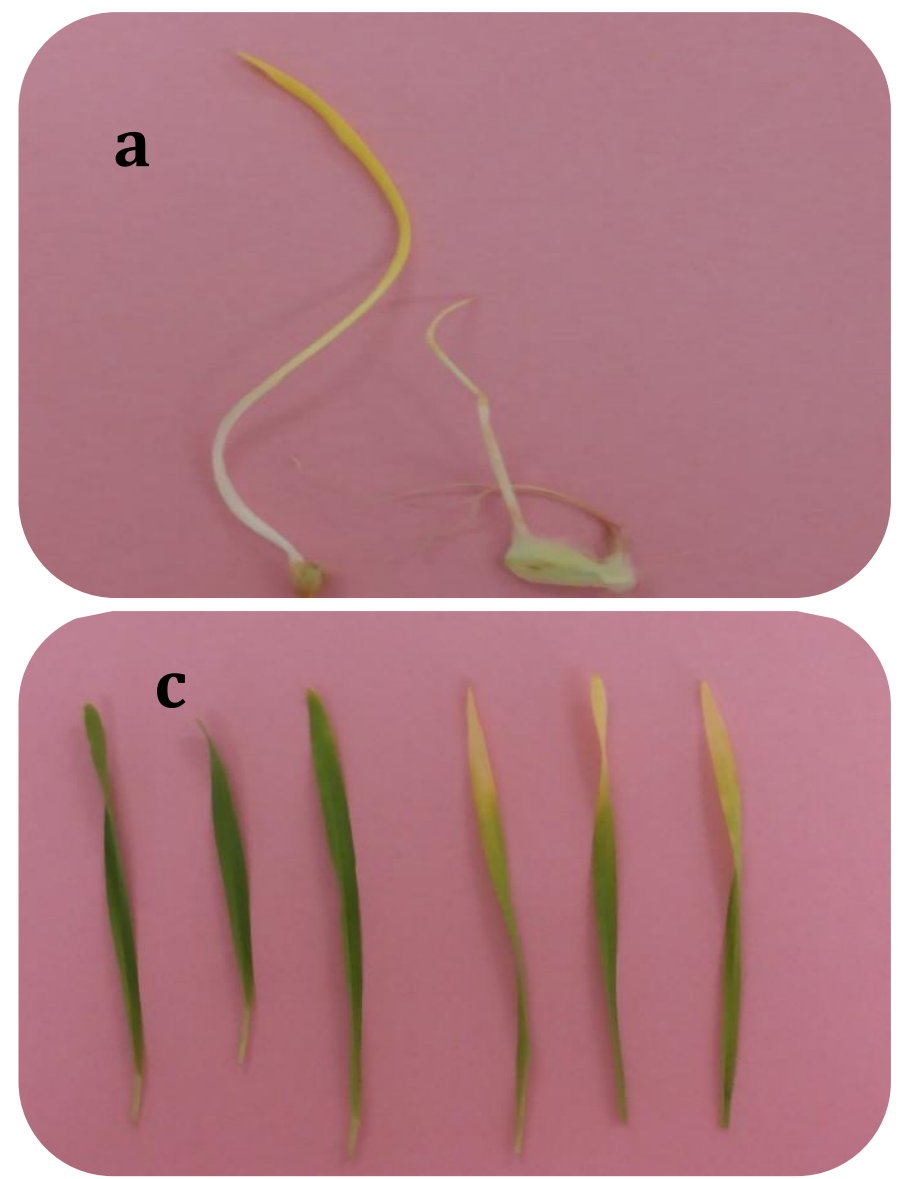

reduced mean values relative to the water controls, suggesting a strong effect of different Fusarium isolates on the growth of these two cultivars (Tables 1, 2 and 3). Seedlings of two barley cultivars growing in the presence of fungal isolates showed typical in vitro FHB symptoms according to three tested assays, whereas the control plants did not show any disease symptoms (Figure 1).

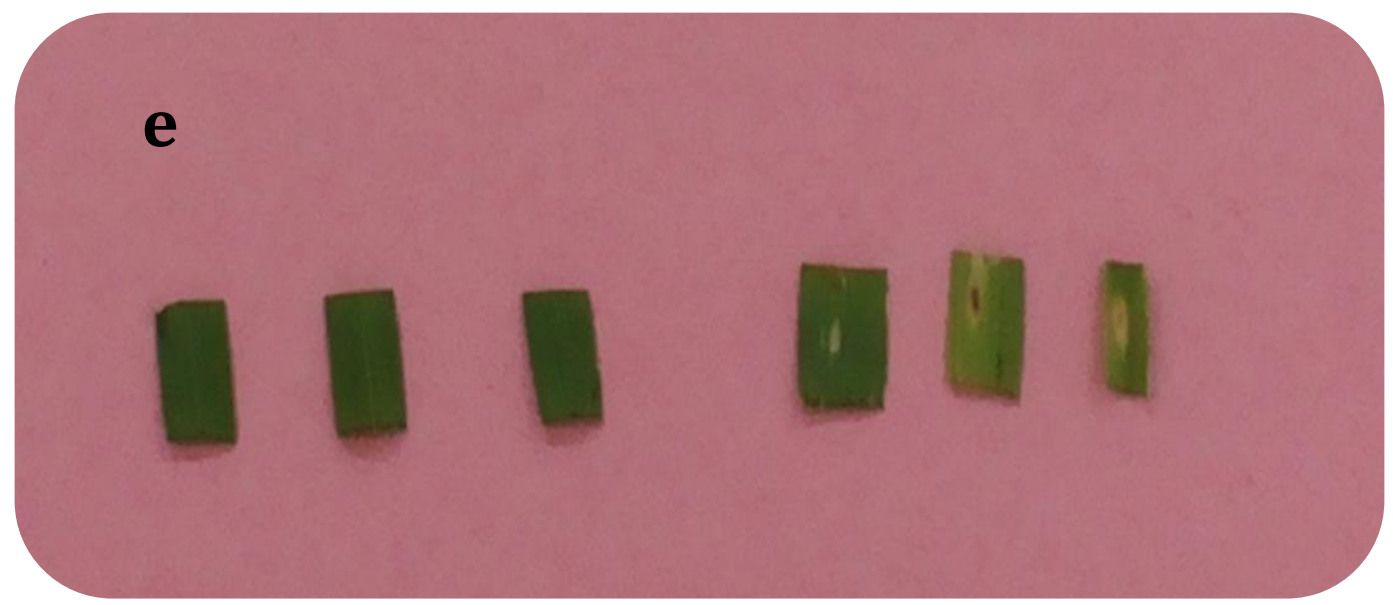

Figure 1. In vitro inoculation assays used to assess Fusarium head blight aggressiveness on plant materials of Syrian barley cultivar Arabi Abiad infected with F30 (F. culmorum), (a) Petri-dish assay, (b) pin-point assay, (c) foliar-spraying assay, (d) clip-dipping assay and (e) detached-leaf assay. 
Table 1 presents mean aggressiveness values determined using in vitro detached leaf assay of FHB isolates on AS and AB. All FHB isolates caused lesions on detached leaves of two barley cultivars by the sixth day post inoculation. No lesions were observed on control leaf segments. Visible lesions were almost oval in shape, appeared as a dull gray-green watersoaked area. No significant differences were indicated among the tested fungal isolates in incubation period ( $\mathrm{P}=0.9997)$ and lesion length $(\mathrm{P}=0.0923)$. The mean incubation period ranged from 1.98 to 2.25 days. The mean lesion length varied from 7.36 to $8.29 \mathrm{~mm}$. For latent period (LP), there were significant differences among the four FHB species and among isolates within each species $(\mathrm{P}=0.0001)$, the two isolates $\mathrm{F} 15$ and F16 (F. verticillioides) showed the greatest aggressiveness, while F7 ( $F$. solani) was the least aggressive isolates. However, the four FHB species did not vary in their LP on the two tested cultivars (Figure 2). Significant correlation was assigned between the values of LP for AS and $\mathrm{AB}\left(\mathrm{r}=0.662^{* *}\right)$.

The values of LP were significantly correlated with previously obtained values of disease incidence generated under controlled on $\mathrm{AB}$ and field conditions on $\mathrm{AS}$ and $\mathrm{AB}$ (Figures 3 and 4) (Sakr, unpublished data), ( $\mathrm{r}=0.848^{* * *}$ for $\mathrm{AS}$, and $\mathrm{r}=635^{* *}$ and $\mathrm{r}=0.559^{*}$ for $\mathrm{AB}$ ). No significant correlation was assigned between LP and disease incidence generated under controlled on AS ( $r=0.319$ not significant). Table 1. Mean aggressiveness values determined using in vitro detached leaf assay in a set of 16 fungal isolates of four Fusarium head blight species measured on two Syrian barley cultivars, Arabi Aswad and Arabi Abiad.

\begin{tabular}{|c|c|c|c|}
\hline $\begin{array}{l}\text { Fungal isolates } \\
\text { (identification) }\end{array}$ & Incubation period Mean (days) & $\begin{array}{c}\text { Latent period } \\
\text { Mean (days) }\end{array}$ & $\begin{array}{l}\text { Lesion length } \\
\text { Mean (mm) }\end{array}$ \\
\hline F1 (F. culmorum) & $2.25 \mathrm{a}$ & $7.90 \mathrm{bc}$ & $8.18 \mathrm{a}$ \\
\hline F2 (F. culmorum) & $2.16 \mathrm{a}$ & $4.69 \mathrm{fg}$ & $7.39 \mathrm{a}$ \\
\hline F3 (F. culmorum) & $2.13 \mathrm{a}$ & $4.68 \mathrm{fg}$ & $7.47 \mathrm{a}$ \\
\hline F28 (F. culmorum) & $2.22 \mathrm{a}$ & $6.03 \mathrm{de}$ & $8.29 \mathrm{a}$ \\
\hline F30 (F. culmorum) & $2.13 \mathrm{a}$ & $8.00 \mathrm{~b}$ & $7.14 \mathrm{a}$ \\
\hline F7 (F. solani) & $2.19 \mathrm{a}$ & $9.22 \mathrm{a}$ & $7.46 \mathrm{a}$ \\
\hline F20 (F. solani $)$ & $2.16 \mathrm{a}$ & $6.77 \mathrm{~cd}$ & $7.22 \mathrm{a}$ \\
\hline F26 (F. solani $)$ & $2.19 \mathrm{a}$ & $6.75 \mathrm{~cd}$ & $7.37 \mathrm{a}$ \\
\hline F29 (F. solani) & $2.19 \mathrm{a}$ & $8.00 \mathrm{~b}$ & $7.22 \mathrm{a}$ \\
\hline F31 (F. solani) & $2.02 \mathrm{a}$ & $5.34 \mathrm{ef}$ & $7.57 \mathrm{a}$ \\
\hline F35 (F. solani $)$ & $2.03 \mathrm{a}$ & $6.52 \mathrm{~d}$ & $8.05 \mathrm{a}$ \\
\hline F15 (F. verticillioides) & $2.02 \mathrm{a}$ & $3.95 \mathrm{~g}$ & $8.00 \mathrm{a}$ \\
\hline F16 (F. verticillioides) & $1.99 \mathrm{a}$ & $4.05 \mathrm{~g}$ & $7.54 \mathrm{a}$ \\
\hline F21 (F. verticillioides) & $1.98 \mathrm{a}$ & $6.23 \mathrm{de}$ & $7.36 \mathrm{a}$ \\
\hline F27 (F. verticillioides) & $2.00 \mathrm{a}$ & $6.04 \mathrm{de}$ & $7.52 \mathrm{a}$ \\
\hline $\mathrm{F} 43$ (F. equiesti) & 2.16 & $6.32 \mathrm{de}$ & $7.64 \mathrm{a}$ \\
\hline Enter isolates & $\mathrm{P}=0.9997$ & $P=0.0001$ & $\mathrm{P}=0.0923$ \\
\hline
\end{tabular}

According to the Fisher's LSD test, means followed by the same letter are not significantly different at $\mathrm{P}>0.05$, Probability (P). Quantitative resistance response of both barley cultivars to 16 tested FHB isolates was analyzed previously and presented by Sakr (2018c). In this study, all fungal isolates were reanalyzed to prove the stability and repeatability of the in vitro detached leaf assay. However, the mean values were added.

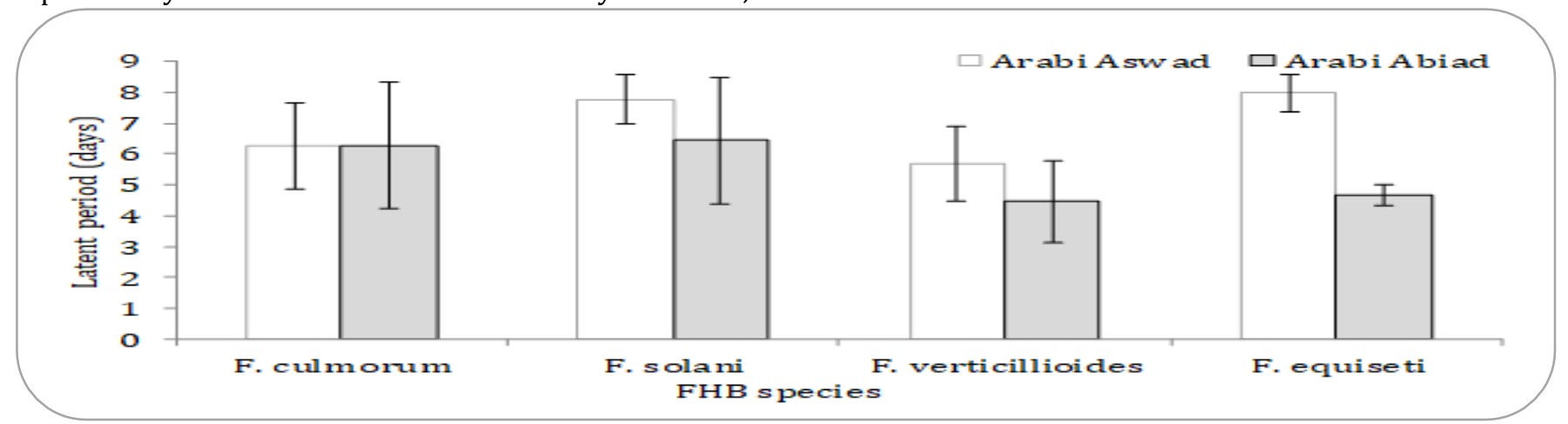

Figure 2. Mean latent period (days) of four Fusarium head blight species on two Syrian barley cultivars, Arabi Aswad and Arabi Abiad detected in an in vitro detached leaf assay. Bars represent the standard errors of means 


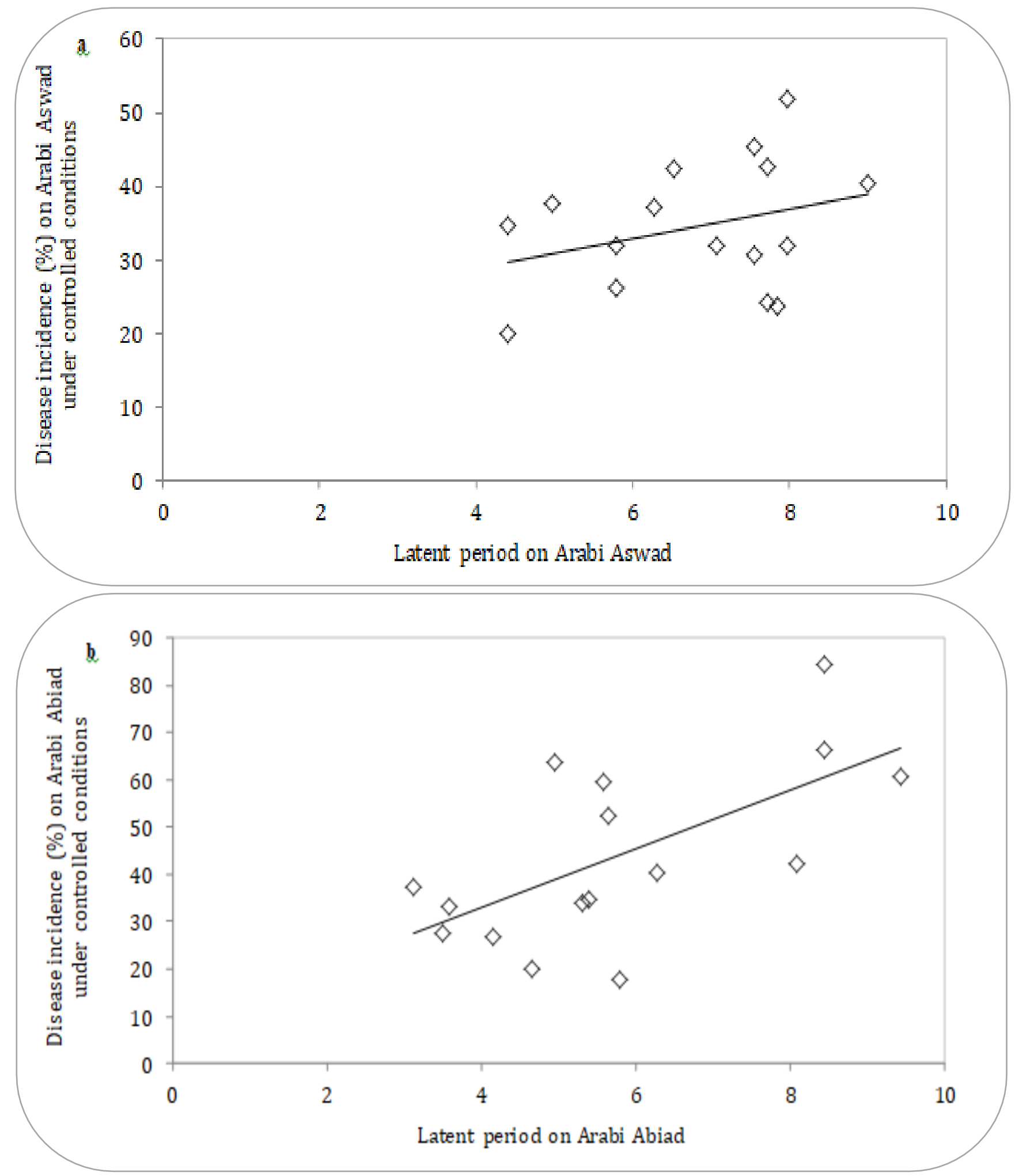

Figure 3. Correlation between latent period and disease incidence under controlled conditions on Arabi Aswad (a) and Arabi Abiad (b) infected with 16 fungal isolates of four Fusarium head blight species determined by Pearson correlation coefficient, $r=0.319$ not significant (a) and $r=635^{* *}(b)$ 


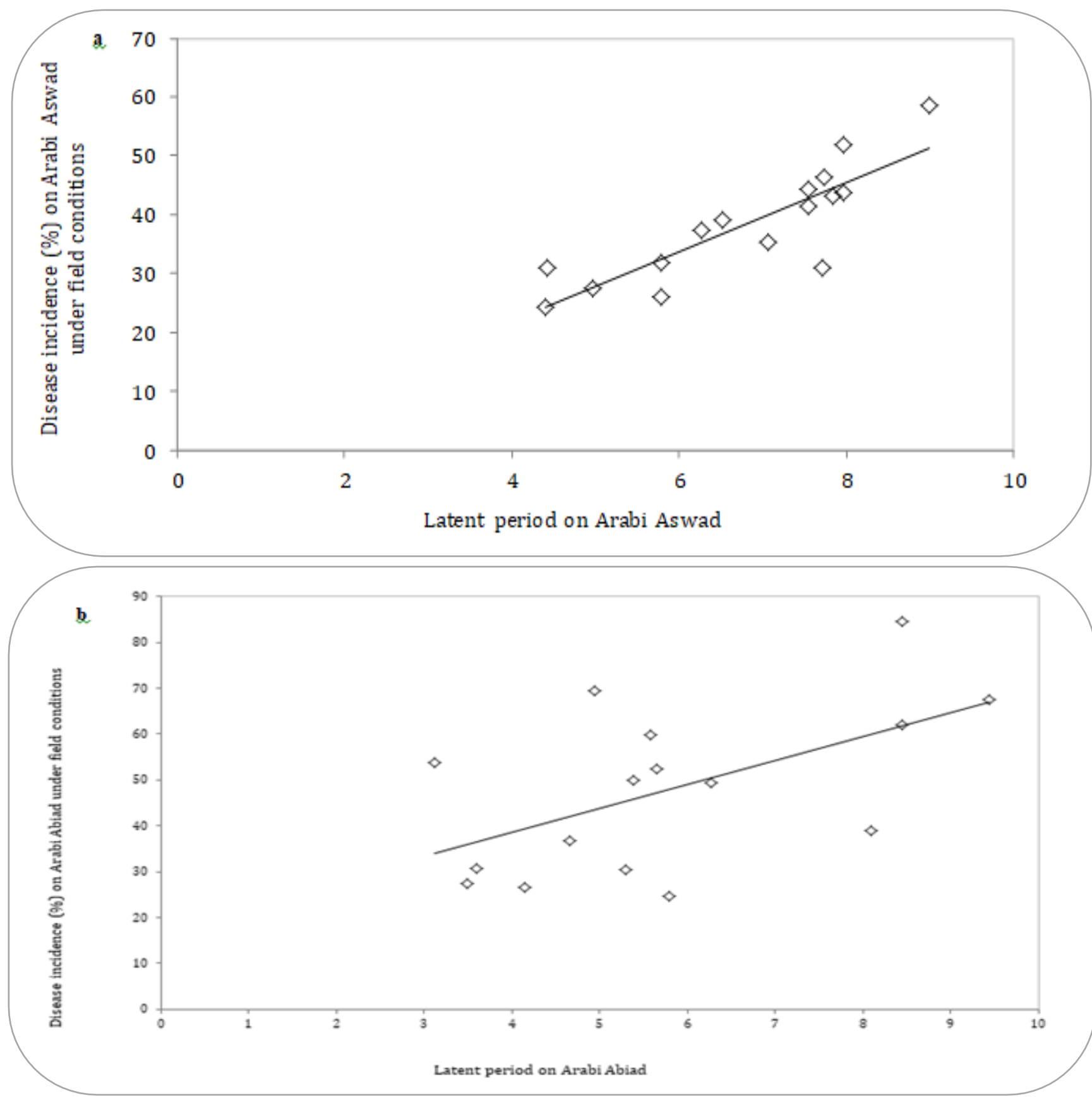

Figure 4. Correlation between latent period and disease incidence under field conditions on Arabi Aswad (a) and Arabi Abiad (b) infected with 16 fungal isolates of four Fusarium head blight species determined by Pearson correlation coefficient, $r=0.848^{* * *}$ (a) and $r=0.559^{*}(\mathrm{~b})$

Table 2 presents mean aggressiveness values determined using in vitro Petri-dish assay of FHB isolates on AS and AB. All the 16 FHB isolates tested with this in vitro assay caused brown spots on the coleoptiles, and/or mycelium that completely covered the seeds of the two tested wheat cultivars. There were no differences among the 16 FHB isolates in germination rate reduction $(\mathrm{P}=0.7825)$ and coleoptile length reduction ( $\mathrm{P}=0.4364)$. Diseased coleoptiles were only one half of mean lengths of healthy coleoptiles that reached $10.3 \mathrm{~mm}$ and $10.1 \mathrm{~mm}$ on $\mathrm{AB}$ and $\mathrm{AS}$, respectively regardless of the FHB isolate. The mean germination rate reduction ranged from 18 to $23 \%$. The mean coleoptile length reduction varied from 52 to $61 \%$. For AUDPC standard, $_{\text {, }}$ significant differences among the four FHB species and among isolates within each species were detected $(\mathrm{P}=0.0001)$, the isolate $\mathrm{F} 7$ ( $F$. solani) showed the greatest 
aggressiveness, while F1 and F2 (F. culmorum), and F15 and F27 (F. verticillioides) was the least aggressive isolates. However, the four FHB species did not vary in their AUDPC $_{\text {standard }}$ on the two tested cultivars (Figure 5). There was a significant correlation between the values of AUDPC $_{\text {standard }}$ for $\mathrm{AS}$ and $\mathrm{AB}\left(\mathrm{r}=0.574^{*}\right)$.

AUDC
Significant correlations were detected between the values of AUDPC $_{\text {standard }}$ and the values of disease incidence generated under controlled and field conditions obtained previously (Figures 6 and 7) (Sakr, unpublished data), $\left(\mathrm{r}=0.533^{*}\right.$ and $\mathrm{r}=0.769^{* * *}$ for $\mathrm{AS}$, and $\mathrm{r}=0.887^{* * *}$ and $\mathrm{r}=0.865^{* * *}$ for $\mathrm{AB}$ ). Fusarium head blight species measured on two Syrian barley cultivars, Arabi Aswad and Arabi Abiad.

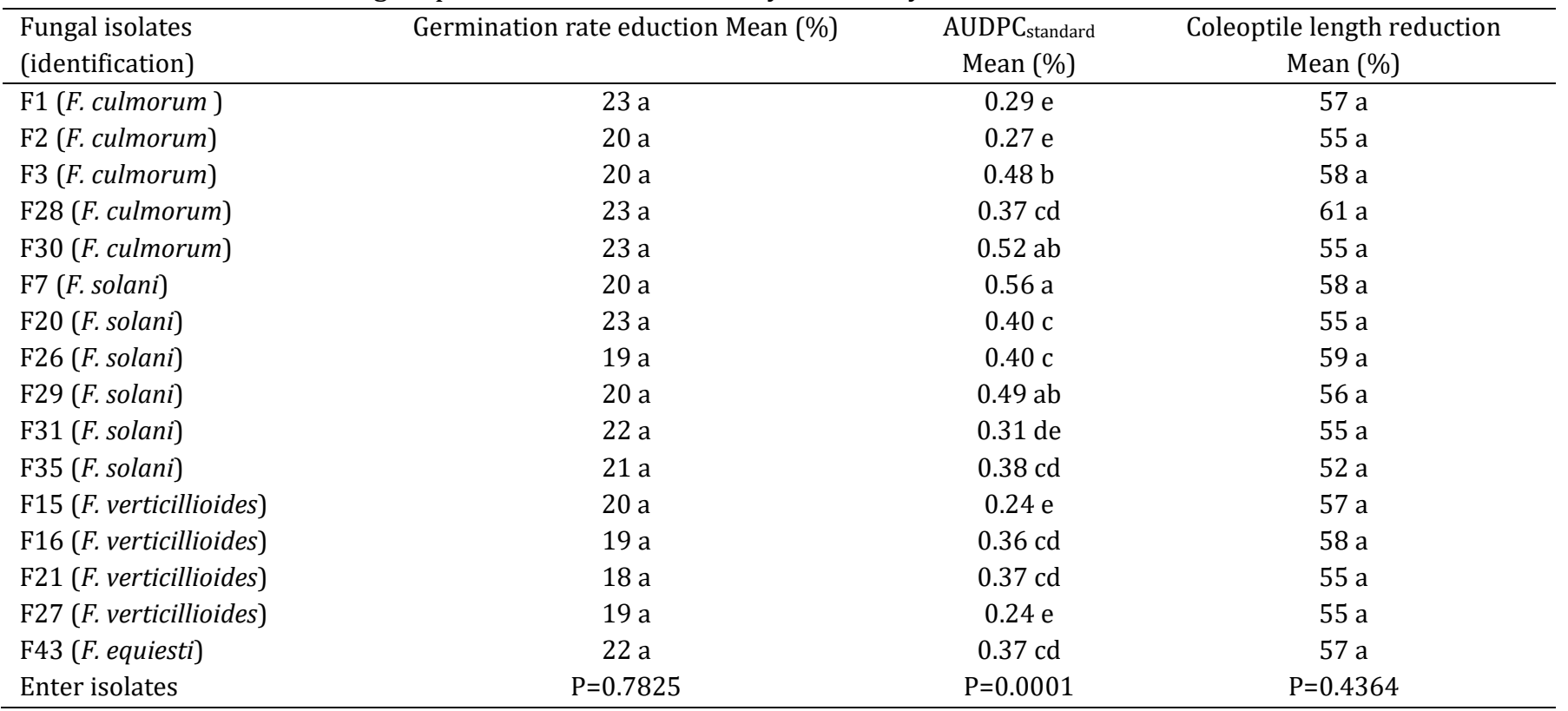

According to the Fisher's LSD test, means followed by the same letter are not significantly different at $P>0.05$, Probability (P). Pathogenic reaction of 16 FHB isolates on Arabi Aswad was analyzed and presented by Sakr (2018b) and quantitative resistance response of both barley cultivars to 16 tested FHB isolates was analyzed previously and presented by Sakr (2018c). In this study, all fungal isolates were reanalyzed to prove the stability and repeatability of the in vitro Petri-dish assay. However, the mean values were added.

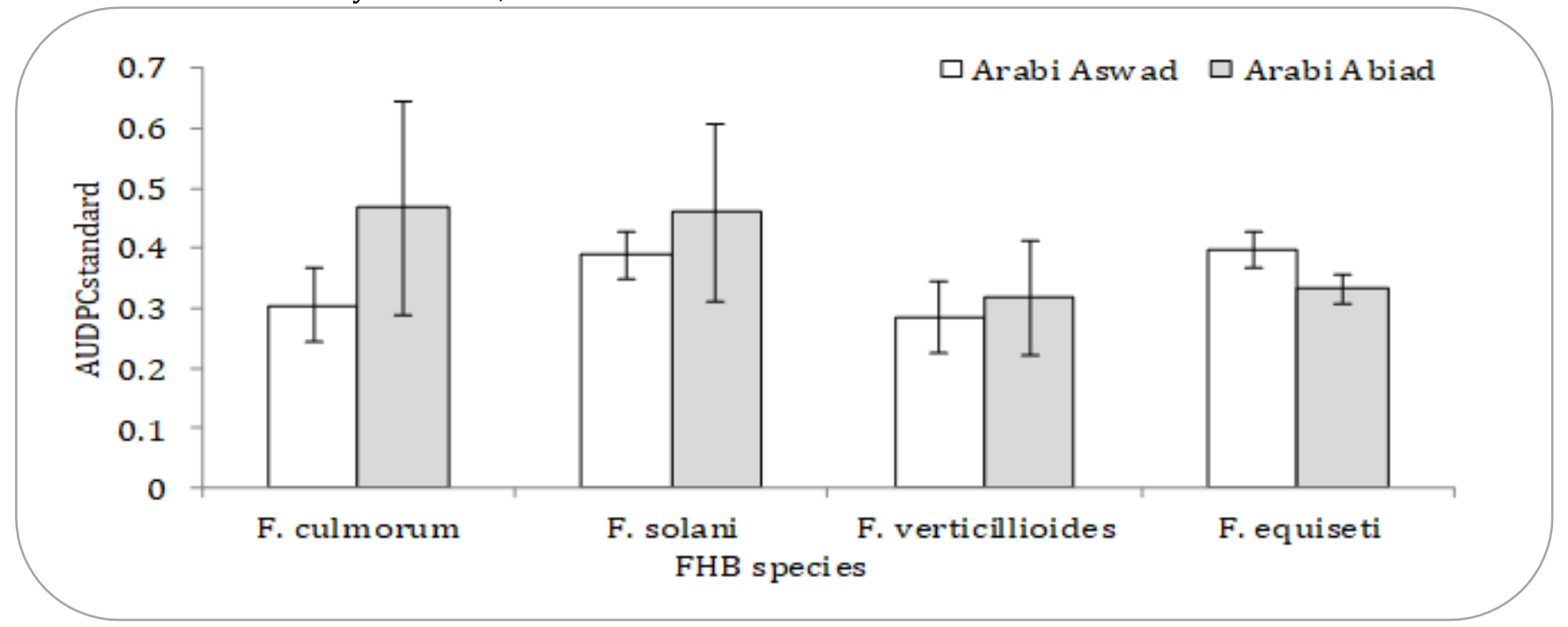

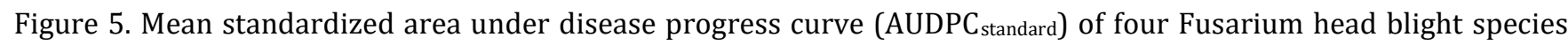
on two Syrian barley cultivars, Arabi Aswad and Arabi Abiad detected in an in vitro Petri-dish assay. Bars represent the standard errors of means 


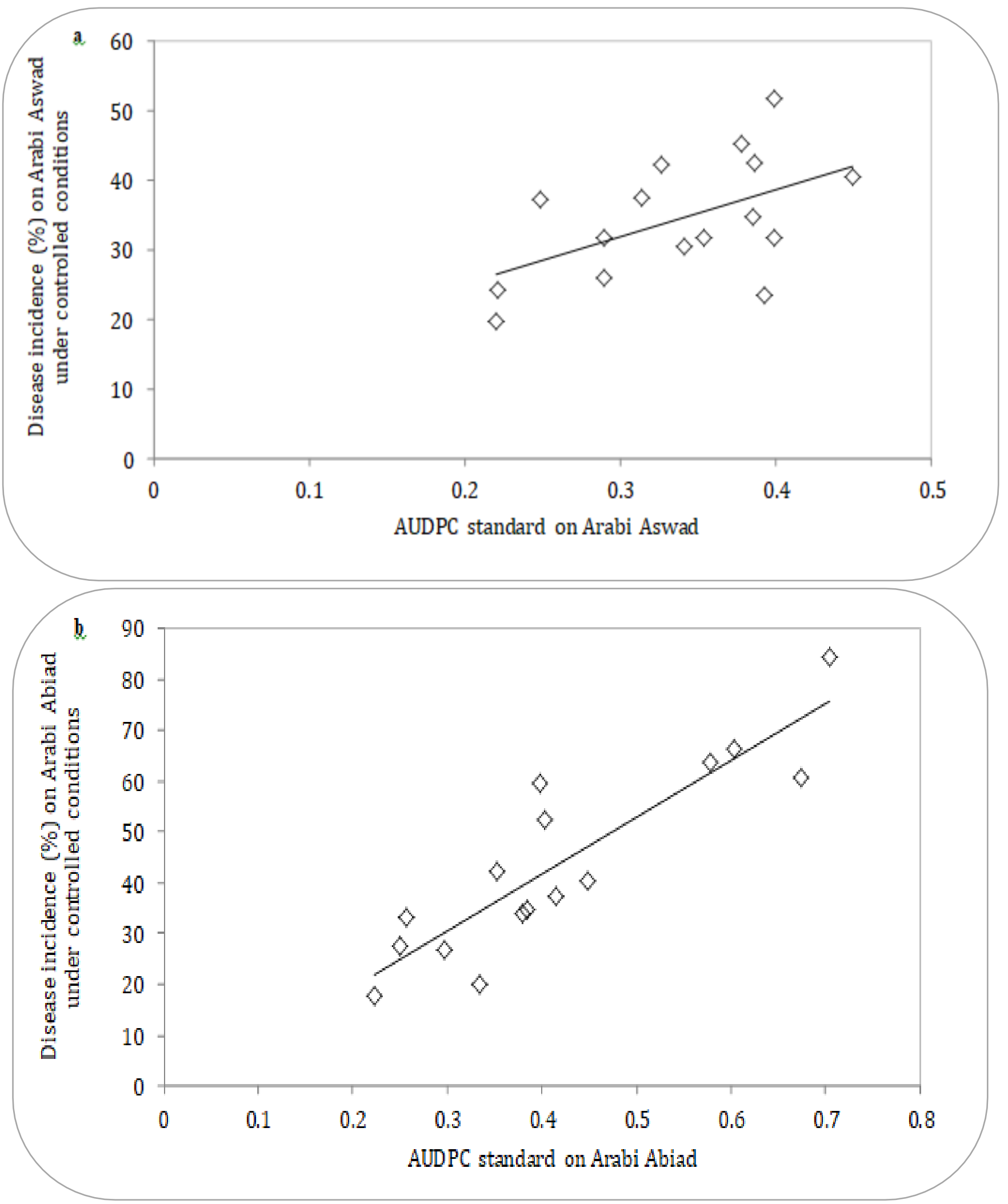

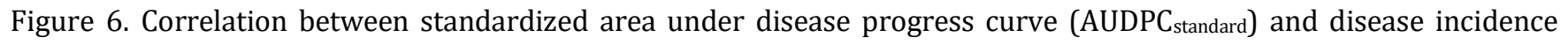
under controlled conditions on Arabi Aswad (a) and Arabi Abiad (b) infected with 16 fungal isolates of four Fusarium head blight species determined by Pearson correlation coefficient, $r=0.533^{*}$ (a) and $r=0.887^{* * *}(b)$ 


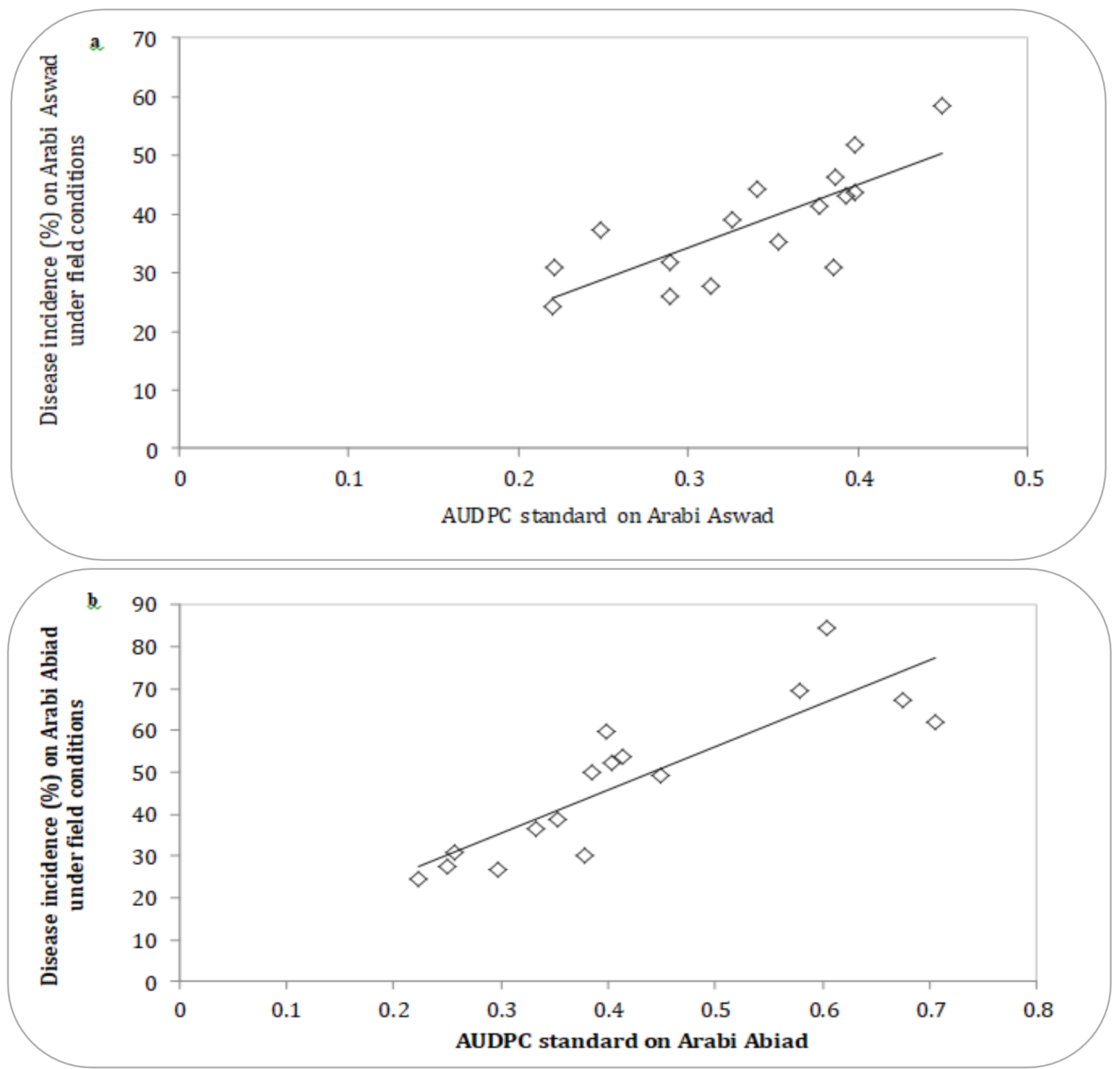

Figure 7. Correlation between standardized area under disease progress curve (AUDPC standard$_{\text {) }}$ and disease incidence under field conditions on Arabi Aswad (a) and Arabi Abiad (b) infected with 16 fungal isolates of four Fusarium head blight species determined by Pearson correlation coefficient, $r=0.769^{* * *}(\mathrm{a})$ and $r=0.865^{* * *}(\mathrm{~b})$

Table 3 presents mean aggressiveness values determined using in vitro seedling assay of FHB isolates on AS and AB. Seedlings inoculated with FHB conidia showed visible fungal disease symptoms within a few days post inoculation. Brown lesions developed from the inoculated sections in three day old seedling coleoptiles and stems. Seven days after inoculation, the seedlings of the two cultivars exhibited varying degrees of visual necrosis as a consequence of the pathogen severity. No significant differences were observed among the 16 tested FHB isolates for the three criteria involved in this assay $(\mathrm{P}=0.9423$ for foliar-spraying, $\mathrm{P}=0.6465$ for pinpoint and $\mathrm{P}=0.9004$ for clip-dipping). The mean percentage of infected seedlings (of spraying inoculation), the mean percentage of infected seedlings (of pin-point inoculation) and the mean lesion length (of clip-dipping inoculation) varied from 38 to $45 \%, 39$ to $44 \%$, and from 1.76 to $2.35 \mathrm{~cm}$, respectively. 
Table 3. Mean aaggressiveness values determined using in vitro seedling assay in a set of 16 fungal isolates of four Fusarium head blight species measured on two Syrian barley cultivars, Arabi Aswad and Arabi Abiad.

\begin{tabular}{|c|c|c|c|}
\hline Fungal isolates (identification) & $\begin{array}{l}\text { Spraying } \\
\text { Mean (\%) }\end{array}$ & $\begin{array}{l}\text { Pin-point } \\
\text { Mean (\%) }\end{array}$ & $\begin{array}{l}\text { Clip-dipping } \\
\text { Mean (cm) }\end{array}$ \\
\hline F1 (F. culmorum ) & $45 \mathrm{a}$ & $44 \mathrm{a}$ & $2.25 \mathrm{a}$ \\
\hline F2 (F. culmorum) & $43 a$ & $41 \mathrm{a}$ & $2.25 \mathrm{a}$ \\
\hline F3 (F. culmorum) & $45 \mathrm{a}$ & $40 \mathrm{a}$ & $2.23 \mathrm{a}$ \\
\hline F28 (F. culmorum) & $45 \mathrm{a}$ & $40 \mathrm{a}$ & $2.27 \mathrm{a}$ \\
\hline F30 (F. culmorum) & $39 a$ & $40 \mathrm{a}$ & $2.13 \mathrm{a}$ \\
\hline F7 (F. solani) & $44 \mathrm{a}$ & $41 \mathrm{a}$ & $2.19 \mathrm{a}$ \\
\hline F20 (F. solani) & $43 \mathrm{a}$ & $40 \mathrm{a}$ & $2.16 \mathrm{a}$ \\
\hline F26 (F. solani) & $44 \mathrm{a}$ & 39 a & $2.19 \mathrm{a}$ \\
\hline F29 (F. solani) & $47 \mathrm{a}$ & $42 \mathrm{a}$ & $2.35 \mathrm{a}$ \\
\hline F31 (F. solani) & $35 \mathrm{a}$ & $38 \mathrm{a}$ & $1.76 \mathrm{a}$ \\
\hline F35 (F. solani $)$ & $38 \mathrm{a}$ & $40 \mathrm{a}$ & $1.89 \mathrm{a}$ \\
\hline F15 (F. verticillioides) & $44 \mathrm{a}$ & $42 \mathrm{a}$ & $1.88 \mathrm{a}$ \\
\hline F16 (F. verticillioides) & $38 \mathrm{a}$ & $40 \mathrm{a}$ & $1.88 \mathrm{a}$ \\
\hline F21 (F. verticillioides) & $42 \mathrm{a}$ & $43 \mathrm{a}$ & $2.08 \mathrm{a}$ \\
\hline F27 (F. verticillioides) & $40 \mathrm{a}$ & $41 \mathrm{a}$ & $2.06 \mathrm{a}$ \\
\hline F43 (F. equiesti) & $45 \mathrm{a}$ & $40 \mathrm{a}$ & $2.25 \mathrm{a}$ \\
\hline Enter isolates & $\mathrm{P}=0.9423$ & $P=0.6465$ & $\mathrm{P}=0.9004$ \\
\hline
\end{tabular}

According to the Fisher's LSD test, means followed by the same letter are not significantly different at $\mathrm{P}>0.05$, Probability (P). Quantitative resistance response of both barley cultivars to 16 tested FHB isolates was analyzed previously and presented by Sakr (2018c). In this study, all fungal isolates were reanalyzed to prove the stability and repeatability of the in vitro seedling assay. However, the mean values were added.

The nine criteria obtained with the three in vitro assays involved in this work were not significantly correlated
(Table 4). Significant correlation was detected between latent period and $\mathrm{AUDPC}_{\text {standard }}\left(\mathrm{r}=0.595^{*}\right)$. Also, there were significant correlation between infected seedlings of foliarspraying inoculation and incubation period $\left(\mathrm{r}=0.726^{* *}\right)$, coleoptile length reduction $\left(\mathrm{r}=0.552^{*}\right)$ and lesion length of clip-dipping inoculation $\left(\mathrm{r}=0.838^{* * *}\right)$, respectively. Moreover, significant correlation was detected between incubation period and latent period $\left(\mathrm{r}=0.559^{*}\right)$, coleoptile length reduction $\left(\mathrm{r}=0.552^{*}\right)$ and lesion length of clipdipping inoculation $\left(\mathrm{r}=0.559^{*}\right)$, respectively.

Table 4. Correlation coefficients on two Syrian barley cultivars (Arabi Aswad and Arabi Abiad) among criteria of aggressiveness for 16 isolates of four Fusarium head blight species

\begin{tabular}{|c|c|c|c|c|c|c|c|c|c|}
\hline & $\begin{array}{c}\text { Incubation } \\
\text { period }\end{array}$ & $\begin{array}{l}\text { Latent } \\
\text { period }\end{array}$ & $\begin{array}{l}\text { Lesion } \\
\text { length }\end{array}$ & $\begin{array}{l}\text { Germination } \\
\text { rate reduction }\end{array}$ & $\mathrm{AUDPC}_{\text {standard }}$ & $\begin{array}{l}\text { Coleoptile } \\
\text { length } \\
\text { reduction }\end{array}$ & $\begin{array}{c}\text { Foliar- } \\
\text { spraying }\end{array}$ & $\begin{array}{l}\text { Pin- } \\
\text { point }\end{array}$ & $\begin{array}{c}\text { Clip- } \\
\text { dipping }\end{array}$ \\
\hline $\begin{array}{l}\text { Incubation } \\
\text { period }\end{array}$ & 1.000 & & & & & & & & \\
\hline Latent period & $0.559^{*}$ & 1.000 & & & & & & & \\
\hline Lesion length & $0.074 \mathrm{~ns}$ & $\begin{array}{c}-0.183 \\
n s\end{array}$ & 1.000 & & & & & & \\
\hline AUDPC $_{\text {standard }}$ & $0.361 \mathrm{~ns}$ & $0.595^{*}$ & $0.453 \mathrm{~ns}$ & $0.088 \mathrm{~ns}$ & 1.000 & & & & \\
\hline $\begin{array}{l}\text { Coleoptile length } \\
\text { reduction }\end{array}$ & $0.522^{*}$ & $\begin{array}{c}-0.020 \\
n s\end{array}$ & $0.284 \mathrm{~ns}$ & $0.022 \mathrm{~ns}$ & $0.150 \mathrm{~ns}$ & 1.000 & & & \\
\hline Foliar-spraying & $0.726^{* *}$ & $0.265 \mathrm{~ns}$ & $0.087 \mathrm{~ns}$ & $0.075 \mathrm{~ns}$ & $0.191 \mathrm{~ns}$ & $0.552^{*}$ & 1.000 & & \\
\hline Pin-point & $0.026 \mathrm{~ns}$ & $0.166 \mathrm{~ns}$ & $0.223 \mathrm{~ns}$ & $-0.200 \mathrm{~ns}$ & $-0.175 \mathrm{~ns}$ & $0.010 \mathrm{~ns}$ & $0.434 \mathrm{~ns}$ & 1.000 & \\
\hline
\end{tabular}

${ }^{*} \mathrm{P}>0.05,{ }^{* *} \mathrm{P}>0.01,{ }^{* * *} \mathrm{P}>0.001, \mathrm{~ns}=$ no significant 


\section{DISCUSSION}

FHB severity on barley plants varied with inoculation methods incorporated several limitations and environmental conditions (Parry et al., 1995; Wu et al., 2005; Chrpova et al., 2011). Development of alternative in vitro approaches that allows for early aggressiveness evaluation, equally effective but less consuming and potentially less resource requiring, is in demand. While the pathogenic responses of FHB isolates used in the current research were recently investigated to explorer the in vitro components of barley quantitative resistance (Sakr, 2018c), the aggressiveness of different FHB species on Arabi Aswad (AS) and Arabi Abiad (AB) was not fully understood in vitro. In this study, all fungal isolates were reanalyzed to prove the stability and repeatability of the three in vitro assays. These important cereal crops are widely distributed along the Fertile Crescent which includes parts of seven countries including Syria (Ceccarelli and Grando, 2000). AS and AB may compose an interesting genetic resource since they possess advantageous agronomic traits (Ceccarelli and Grando 2000), including acceptable levels of resistance to FHB (Sakr, 2018c). To our best knowledge, this is the first in vitro research full analyzing aggressiveness of four FHB species on barley plants. In addition, our study investigates the potential use of in vitro indices in predicting FHB data generated under controlled and field conditions.

The experimental conditions governed in the three tested in vitro assays can stimulate the interaction between barley tissues and fungi. The situation in detached leaf, Petri-dish and seedling assays was similar to spray inoculation under controlled and field conditions because FHB species need to overcome the morphology of the head spike and they could directly penetrate and infect germinating seeds (Sakr, 2018c, 2019). Thus, disease development is manifested through appearance of symptoms such as brown spots on the coleoptiles and/or by mycelium completely covering the seeds, discoloured, malformed, necrotic or chlorotic areas on the affected plant part (Figure 1).

Differences in inoculated treatment were observed on young AS and $\mathrm{AB}$ parts relative to water controls (Tables 1, 2 and 3). This indicates that the three tested assays conducted on M. nivale, F. graminearum and the four tested FHB species to assess quantitative wheat and barley resistance (Mesterhazy 1978; Browne and Cooke 2005; Shin et al., 2014; Sakr, 2018c, 2019) can distinguish significant differences between control treatments and barley plants infected with FHB species: $F$. culmorum, $F$. verticillioides, $F$. solani and $F$. equiseti. All the fungal isolates tested with the in vitro detached leaf, Petri-dish and seedling assays fulfilled the capability to stimulate FHB disease, thus they are pathogenic. The ability of 16 fungal isolates to cause chlorosis and necrosis in different amounts on barley leaves and seedlings may be due to that the four FHB species analyzed in this study produce several mycotoxins which have been found to manifest symptoms in plant tissues (Xu and Nicholson, 2009).

Short incubation period and latent period, long lesion length, high percentage of infected seedlings and important reduction in the length of the hypocotyl represent high aggressiveness (Lannou, 2012). The seven in vitro criteria: incubation period (IP) and lesion length (LL) of detached leaf test, germination rate reduction (GRR) and coleoptile length reduction (CLR) of Petri-dish assay, percentage of infected seedlings (of foliar-spraying and pin-point inoculations) and lesion length (LL) of seedling test did not distinguish 16 fungal isolates (Tables 1, 2 and 3). Our findings agree with in vitro previous GRR and CLR data in which these two criteria did not distinguish the same fungal isolates on barley and wheat plants (Sakr, 2017b, 2018a,b,e,f). Contrary to our data, variation in the aggressiveness as measured by LL (of detached-leaf assay) was detected of different F. langsethiae isolates (Opoku et al., 2011). Latent period (LP) and standardized area under disease progress curve (AUDPC $_{\text {standard}}$ ) underlined intra- and inter-species variability in aggressiveness (Tables 1 and 2). Our findings are in accordance with those found by Sakr (2017b, 2018a,b,e,f) in which differences in pathogenicity were detected using AUDPC $_{\text {standard }}$ on barley and wheat plants. Inter and intraspecific differences were observed in aggressiveness of several FHB species toward barley genotypes (Xue et al., 2006; Garmendia et al., 2018). Mutation, genetic recombination or selection may play an important role in the pathogenesis.

The variability in aggressiveness among the 16 fungal isolates observed in our research may cause difficulties in diagnosing FHB disease in the field and prevent the timely application of control measures (Chrpova et al., 2011). Moreover, the existence of high variation in the four FHB species also underlines the need for breeders to include a broad range of isolates in their screening for 
selection of FHB resistant cultivars (Malihipour et al., 2012). The using of highly aggressive FHB isolates as an effective tool for achieving adequate differentiation among host cultivars and selecting barley cultivars with high levels of resistance to FHB is recommended in FHB nurseries and barley breeding programs. In addition, use of a mixture of FHB isolates of the four tested FHB species should be preferred for artificial inoculations reflecting the conditions that occur in natural epidemics (Malihipour et al., 2012).

Results shown in Figures 2 and 5 indicated an overall homogeneous comparative aggressiveness in the four FHB species because of similarity in damage among the 16 fungal isolates. Similarly, Sakr (2018a,b,e,f) did not cluster the same fungal species on AS and durum and bread wheat cultivars using AUDPC standard. Fernandez and Chen (2005) observed an apparent lack of a difference in aggressiveness between $F$. culmorum and $F$. graminearum on wheat. Our results did not support previous reports showing that FHB species were classified as highly, moderately and weakly pathogenic on barley and wheat plants (Xue et al., 2004; Xue et al., 2006; Malihipour et al., 2012). F. culmorum and F. equiseti, included in the present research, was recognized to be highly and weakly pathogenic, respectively, among several examined FHB species (Xue et al., 2004; Xue et al., 2006; Malihipour et al., 2012). The differences in these data may be attributable to the contrasting isolates and host cultivars used in this study and pervious work. Sakr (2018a) hypothesized that the origin of FHB cultures may play a crucial role in this pathogenic similarity.

Results of the present study add to our expanding knowledge that cultivar-specific aggressiveness has not been detected. Significant correlations were detected between the values of latent period and AUDPC $_{\text {standard }}$ on any of the two tested cultivars infected with 16 fungal isolates of four species. Our results agree with pervious data showing that no evidence for cultivar-specific aggressiveness, for instance between the values of AUDPC $_{\text {standard }}$ on both: durum wheat cultivar Cham7 and AS (Sakr, 2018b) and Cham9 (durum) and Bohoth10 (bread) wheat cultivars (Sakr, 2018a). A possibility of a cultivar-specific aggressiveness has been shown between the values of disease incidence for $\mathrm{AS}$ and $\mathrm{AB}$ under growth chamber conditions ( $\mathrm{r}=-0.115$ not significant) (Sakr, unpublished data) and between the

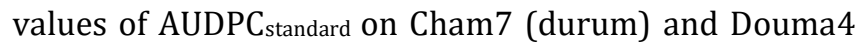

(bread) wheat cultivars (Sakr, 2018e,f). This type of interaction has previously been reported by Foroud et al., (2012), who reported that F. graminearum aggressiveness is host-dependent. In this pathosysteme, no strong evidence for species-specific in wheat and barley to any of the fungal species implicated in the FHB complex (Parry et al., 1995).

Aggressiveness criteria detected in detached leaf, modified Petri-dish and seedling assays were not correlated (Table 4), suggesting that these criteria are genetically distinct, and also reflecting into complex polygenic nature of aggressiveness in the interaction in FHP-barley system. The results provide evidence that individual aggressiveness criterion differentially influence aspects of FHB disease development in barley plants (Tables 1, 2 and 3). Regarding criteria in which variation in aggressiveness were assigned, significant correlation was detected between LP and AUDPC $C_{\text {standard. }}$ The results provide evidence that the mechanisms underlying LP and AUDPC $_{\text {standard }}$ did share the same genetic background. The level of quantitative resistance in $A S$ and $A B$ made it possible to detect significant differences between FHB isolates (Tables 1 and 2). Although the most FHB resistant barley cultivars exhibit poor agronomical characteristics (Chrpova et al., 2011), the variability of resistance for AS and AB (Sakr 2018c), with the highest agronomic traits (Ceccarelli and Grando, 2000), is promising resistance sources to FHB for introgression in barley breeding.

This research supports the view that the correlations of different aggressiveness indices exist and are stable with in vitro, under controlled and field conditions (Figures 3 , 4,6 and 7), suggesting that in vitro indices can predict pathogenic traits generated under several experimental conditions. Results indicted that the in vitro aggressiveness tests conducted in FHB species ( $F$. culmorum, $F$. verticillioides, $F$. solani and $F$. equiseti) are repeatable and stable with $\mathrm{AS}$ and $\mathrm{AB}$ barley plants under controlled and field conditions. AUDPC $C_{\text {standard }}$ and latent period could reflect aspects of pathogen development at early stages of plant growth by promoting the interaction between barley tissues and fungi. The biological explanation for an association between early and late plant responses to FHB infection remains largely speculative, but it can be hypothesized that similar genetic pathways become activated at both developmental stages. AUDPC standard $_{\text {and latent period }}$ are indicators of aggressiveness occurring in the whole 
plant during FHB infection. Since only two barley cultivars were analyzed here, further research using a large sample of available Syrian barley cultivars is needed to validate our aggressiveness data generated under in vitro, controlled and field conditions.

\section{ACKNOWLEDGEMENTS}

The author would like to thank Director General of AECS and the Head of the Agriculture Department for their support. The unknown Reviewer is thanked for constructive comments on this manuscript.

\section{REFERENCES}

Backhouse, D. and L. W. Burgess. 2002. Climatic analysis of the distribution of Fusarium graminearum, F. pseudograminearum and F. culmorum on cereals in Australia. Australas. Plant Pathol. 31: 321.

Bilikova, J. and K. Hudec. 2014. Occurrence of Fusarium head blight of barley in Slovakia. Journal of Central European Agriculture, 15: 175-184.

Bishawa, Z., P. C., Struikb and A. J. G. van Gastelc. 2015. Wheat and barley seed system in Syria: How diverse are wheat and barley varieties and landraces from farmer's fields? International Journal of Plant Production, 9: 117-150.

Browne, R. A. and B. M. Cooke. 2005. A comparative assessment of potential components of partial disease resistance to Fusarium head blight using a detached leaf assay of wheat, barley and oats. European Journal of Plant Pathology, 112: 247258.

Canci, P. C., L. M. Nduulu, G. J., Muehlbauer, R., DillMacky, D. C., Rasmusson, and K. P. Smith. 2004. Validation of quantitative trait loci for Fusarium head blight and kernel discoloration in barley. Molecular Breeding, 14: 91-104.

Ceccarelli, S. and S. Grando. 2000. Barley landraces from the Fertile Crescent: a lesson for plant breeders. By S. B. Brush, Canada: International Development Research Centre, $1^{\text {st }}$ ed., pp. 51-76.

Chrpova, J., V. Sip, L. Stockova, L. Stemberkova and L. Tvaruzek. 2011. Resistance to Fusarium head blight in spring barley. Czech. Journal of Genetics and Plant Breeding, 47: 58-63.

De Galich, M. T. V. 1997. Fusarium head blight in Argentina. FAO. http://agris.fao.org/agrissearch/search.do?recordID=QY1998000293.

Foroud, N. A., S. P. McCormick, T. MacMillan, A. Badea, D. F. Kendra, B. E. Ellis and F. Eudes. 2012. Greenhouse studies reveal increased aggressiveness of emergent Canadian Fusarium graminearum chemotypes in wheat. Plant Disease 96: 1271-1279.

Fernandez, M. R and Y. Chen. 2005. Pathogenicity of Fusarium species on different plant parts of spring wheat under controlled conditions. Plant Disease, 89: 164-169.

Garmendia, G., L. Pattarino, C. Negrin, A, MartínezSilveira, S. Pereyra, T. J. Ward and S. Vero. 2018. Species composition, toxigenic potential and aggressiveness of Fusarium isolates causing Head Blight of barley in Uruguay. Food Microbiology, 76: 426-433.

Hestbjerg, H., G. Felding and S. Elmholt. 2002. Fusarium culmorum infection of barley seedlings: correlation between aggressiveness and deoxynivalenol content. Journal of Phytopathology 150: 308-312.

Lannou, C. 2012. Variation and selection of quantitative traits in plant pathogens. Annual Review of Phytopathology, 50: 319-338.

Malihipour, A., J. Gilbert, M., Piercey-Normore and S. Cloutier. 2012. Molecular phylogenetic analysis, trichothecene chemotype patterns, and variation in aggressiveness of Fusarium isolates causing head blight in wheat. Plant Disease. 96: 10161025.

Mesterhazy, A. 1978. Comparative analysis of artificial inoculation methods with Fusarium spp. on winter wheat varieties. Journal of Phytopathology 93:12-25.

Nelson, P. E., T. A. Toussoun and W. F. O. Marasas. 1983. Fusarium Species: An Illustrated Manual for Identification. Penn. State Univ. Press, PA. USA.

Nielsen, L. K., D. J. Cook, S. G. Edwards and R. V. Ray. 2014. The prevalence and impact of Fusarium head blight pathogens and mycotoxins on malting barley quality in UK. International Journal of Food Microbiology,179: 38-49.

Opoku, N., M. Back and S. Edwards. 2011. Aggressiveness of Fusarium langsethiae isolates towards wheat, barley and oats in an in vitro leaf assay. Plant Breeding and Seed Science, 64: 55-63.

Parry, D. W., P. Jekinson and L. MCleod. 1995. Fusarium ear blight (scab) in small grain cereals-a review. Plant Pathology, 44: 207-238.

Purahong, W., D. Alkadri, P. Nipoti, A. Pisi, M. Lemmens and A. Prodi. 2012. Validation of a modified Petri- 
dish test to quantify aggressiveness of Fusarium graminearum in durum wheat. European Journal of Plant Pathology. 132: 381-391.

Sakr, N. 2017a. Aggressiveness of four Fusarium head blight species on wheat cultivars. Advances in Horticultural Science, 31: 199-203.

Sakr, N. 2017b. In vitro assessment of Fusarium head blight spp. on wheat cultivars. Archives of Phytopathology and Plant Protection, 50: 254261.

Sakr, N. 2018a. Aggressiveness of Fusarium head blight species towards two modern Syrian wheat cultivars in an in vitro Petri-dish. Cereal Research Communications, 46: 480-489.

Sakr, N. 2018b. Aggressiveness variation among and within Fusarium head blight species on barley in vitro. Acta Phytopathologica et Entomologica Hungarica, 53: 1-10.

Sakr, N. 2018c. Components of quantitative resistance in barley plants to Fusarium head blight infection determined using three in vitro assays. Journal of Plant Protection Research, 58: 176-183.

Sakr, N. 2018d. Evaluation of two storage methods for fungal isolates of Fusarium sp. and Cochliobolus sativus. Acta Phytopathologica et Entomologica Hungarica,53: 11-18.

Sakr, N. 2018e. Interaction between Triticum aestivum plants and four Fusarium head blight species on the level of pathogenicity: detected in an in vitro Petri-dish assay. Acta Phytopathologica et Entomologica Hungarica, 53: 171-179.

Sakr, N. 2018f. Intra- and inter-species variability of the aggressiveness in four Fusarium head blight species on durum wheat plants detected in an in vitro Petri-dish assay. Archives of Phytopathology and Plant Protection, 51: 814-823.

Sakr N. 2019. In vitro quantitative resistance components in wheat plants to Fusarium head blight. The Open Agriculture Journal, 13:9-18.

Saharan, M. S., J. Kumar, A. K. Sharma and Nagarajan S. 2003. Pathogenic variation among Fusarium spp. associated with head scab in India. Indian Journal of Agricultural Sciences 73: 322-326.

Shin, S., K. H. Kim, C. S. Kang, K. M. Cho, C. S. Park, R. Okagaki and J. C. Park. 2014. Simple method for the assessment of Fusarium head blight resistance in Korean wheat seedlings inoculated with Fusarium graminearum. The Plant Pathology Journal, 30: 25-32.

Wu, A. B., H.P. Li, C. S. Zhao and Y. C. Liao. 2005. Comparative pathogenicity of Fusarium graminearum isolates from China revealed by wheat coleoptile and floret inoculations. Mycopathologia 160: 75-83.

$\mathrm{Xu}, \mathrm{X}$ and P. Nicholson. 2009. Community ecology of fungal pathogens causing wheat head blight. Annual Review of Phytopathology. 47: 83-103.

Xue, A. G., K. C. Armstrong, H. D. Voldeng, G. Fedak and Babcock C. 2004. Comparative aggressiveness of isolates of Fusarium species causing head blight on wheat in Canada. Canada Journal of Plant Pathology, 26: 81-88.

Xue, A. G., K. M. Ho, G. Butler, B. J. Vigier and C. Babcock. 2006. Pathogenicity of Fusarium species causing head blight in barley. Phytoprotection 87: 55-61. 